\title{
General Psychiatry Mental health service users' progression from illicit drug use to schizophrenia in New Zealand
}

\author{
Graham Mellsop, ${ }^{1}$ Rees Tapsell, ${ }^{2}$ Pragya Holmes ${ }^{1}$
}

To cite: Mellsop G, Tapsell R, Holmes P. Mental health service users' progression from illicit drug use to schizophrenia in New Zealand. General Psychiatry 2019;32:e100088. doi:10.1136/ gpsych-2019-100088

Received 15 May 2019

Revised 09 August 2019

Accepted 15 August 2019
Check for updates

(C) Author(s) (or their employer(s)) 2019. Re-use permitted under CC BY-NC. No commercial re-use. See rights and permissions. Published by BMJ.

${ }^{1}$ Research Contractor, Auckland, New Zealand

2University of Auckland Waikato Clinical School, Hamilton, New Zealand

Correspondence to Dr Graham Mellsop; graham.mellsop@waikatodhb. health.nz

\section{ABSTRACT}

Background Recently, publications have hypothesised that the demonstrated increase in the incidence of schizophrenia in New Zealand is a side effect of the increased strength of available cannabis derivatives over the last 25+ years and the much more recent increase in the population's use of methamphetamine.

Aim To compare the rates of later schizophrenia between age-matched mental health service users with initial diagnoses as alcohol abusers or illicit drug users. Method From the PRIMHD comprehensive national database, all users of the mental health services over a 5-year period who received an ICD-10 presenting diagnosis of alcohol or substance use/abuse were identified. For each person identified, the database was examined for the following 3 years to determine the numbers later diagnosed with schizophrenia.

Results For the initial alcohol problem people in their twenties, $1.7 \%$ were diagnosed as suffering from schizophrenia in the subsequent 3 years. For the initial drug problem people, the rate was $10.9 \%$. Within that drug-using population, the indigenous Maori developed schizophrenia at a higher rate than did the remainder of the population.

Conclusion These findings in New Zealand require further research into their generalisability, context and explanation.

Although in their daily work clinicians often use the term schizophrenia as though it is a precise diagnostic entity, official classifications and textbooks have usually recognised that the term refers to a syndrome with a variety of likely pathogenetic contributors. ${ }^{1}$ Variable genetic predisposition with possibly multiple environmental enhancers has been the most defended position. ${ }^{2-4}$ High incidence populations have usually been considered to probably reflect the existence of particular stressors on those groups. ${ }^{35}$

Until this millennium, the epidemiology of most mental illnesses in New Zealand has been mainly understood by extrapolation from studies undertaken in other countries supplemented by predominantly public hospital statistics and more qualitative observations or comments. In the last 50 years, a variety of authors have moved from expressing concerns about an apparent under-utilisation of mental health services by the Polynesian, indigenous Maori ${ }^{6}$ to recognition and quantification of their over-representation, at least as reflected in service user populations. The first purpose-designed, community-based study conducted in New Zealand concluded that in only two diagnostic groups were Maori statistically significantly over-represented. ${ }^{7}$ One of those categories was substance abuse disorders or problems. That study was not able to comment on the rates of schizophrenia due to the relative rarity of that disorder in such a community-based survey. In recent years, two groups of researchers have attempted to quantify the relative epidemiology of schizophrenia between Maori and non-Maori. ${ }^{8} 9$ Using quite different research designs, they appear to have demonstrated significantly increased prevalence and incidence of the diagnosed clinical disorder schizophrenia in Maori, when compared with the remainder of the New Zealand population. The reported twofold to threefold increases far exceed any increased rates which could be explained by cross-culturally uninformed misdiagnosis. There is no evidence that this increased rate of the serious disorder, schizophrenia, existed in most of the last century.

The ability of some illicit drugs, particularly methamphetamine and stronger forms of cannabis, to produce a psychotic disorder which mimics schizophrenia in its course and chronicity although raised in Swedish prospective research published in The Lancet in $1987^{10}$ has only been described with more confidence in reviews published in this millennium. ${ }^{11-13}$ Accordingly, we now know that some persons with schizophrenia suffer from it because of the extent of their earlier cannabis or methamphetamine use. With both cannabinoids and methamphetamine, the increased risk of later schizophrenic psychosis is dose (frequency and quantity of 
use) related. ${ }^{11} 1314$ The strengths of cannabis available in New Zealand has been shown to have increased in the last 30 years. $^{15}$

It is now also clear that the availability and use of methamphetamines has risen exponentially in New Zealand over the last 10 years. A New Zealand Police Insight Report of April 2018 notes that the numbers arrested and detained while under the influence of methamphetamine increased approximately 10-fold in the period 2010 to 2017. Interestingly, a fivefold increase in amphetamine-related hospital admissions in Australia in the period 2009 to 2015 has been recently noted by Sara et al. ${ }^{16}$

\section{HYPOTHESIS}

We have hypothesised ${ }^{17}$ that the demonstrated increased rate of schizophrenia in New Zealand is a consequence of the increased rate of use of high-potency cannabis over the last 30 years and the more recent increase in methamphetamine use. We have also noted the potential relevance of such a view to preventive actions. ${ }^{18}$

If there is an increase in the rate of schizophrenia in New Zealand as a consequence of an increase in the population use of methamphetamine and/or more potent preparations of cannabis, then an increased number of young people who present to drug and alcohol services with substance(mis) use issues would be expected to later develop schizophrenia. The existence of the PRIMHD database which records particular information about all episodes of care provided in the New Zealand public mental health and drug and alcohol services allows an opportunity to examine such progressions.

\section{RESEARCH AIM}

By using the PRIMHD database which is the mental health and addiction database of service activity and outcomes for people accessing services nationwide, our study aims to establish how often young New Zealanders who present to the drug and alcohol services proceed, over the subsequent 3-year period, to exhibit the clinical picture of schizophrenia and to determine if such progression is more common in those whose drug use is particularly cannabis and/or methamphetamine than in those who primarily use alcohol. Because of our earlier hypothesis and New Zealand's concerns at the apparent over-representation of Maori in many of our mental health services, cultural correlations will be particularly examined.

\section{METHOD}

The PRIMHD database was screened by the Ministry of Health to provide us with non-identifiable information for all of those who had a first inpatient admission to mental health and alcohol and drugs services in the 5-year period 2010-2014 and received one of the ICD-10 alcohol and drug diagnoses. Those lying outside the age range of 15-30 at their presentation were excluded. For each person, subsequent admissions as recorded in the PRIMHD database were then extracted. This allowed a subsequent 3-year follow-up for those presenting in any year. That database was further analysed by us.

It has been demonstrated that clinicians using the ICD-10 system in their daily work show acceptable reliability of diagnosis for overarching groups, but not for subgroups. ${ }^{19}$ Our analysis was therefore limited to a comparison of the subsequent rates of schizophrenia between the initial alcohol presenters and the grouped illicit drug users. This was also because although the coding in the PRIMHD database identified separate cannabis and methamphetamine subgroups, inspection of the data indicated that clinicians more often recorded drug users under the coding which allowed for more than one substance use or an unknown mixture by that individual.

New Zealand Police Report dated 5 April 2018 was provided to the authors on 22 May 2018.

\section{ETHICS}

All the analyses were only of grouped data, with no individual identification.

\section{RESULTS}

The annual numbers of New Zealanders diagnosed with an alcohol or substance abuse disorder $(<10000 /$ year $)$ did not change significantly over the 5 years $(2010-2014)$ except for a doubling in the total numbers of those where the substance abused was recorded as an amphetamine. The median age of presentation for both the alcohol and substance abusing groups was 22 years. Within the substance abuse group, the cannabis users presented earlier (median age 21years) than the methamphetamine users (24years).

Only $1.7 \%$ of those presenting with an alcohol problem were diagnosed with schizophrenia in the subsequent 3years: $3.3 \%$ for Maori and $1.1 \%$ for non-Maori (table 1 ). It appears that in the alcohol abusing population,

\begin{tabular}{lccll}
\hline \multicolumn{4}{l}{ Table 1} & \multicolumn{4}{l}{ Percentages of those who were diagnosed with schizophrenia within 3years of initial drug or alcohol presentation } \\
\hline Diagnostic group & Maori & Non-Maori & Maori-schizophrenia (\%) & Non-Maori-schizophrenia (\%) \\
\hline Alcohol use & 5100 & 13222 & $168(3.3)$ & $147(1.1)$ \\
Drug use & 2861 & 5880 & $527(18.4)$ & $432(7.3)$ \\
Total & 7961 & 19102 & $695(8.7)$ & $579(3.0)$ \\
\hline
\end{tabular}


Maori develop schizophrenia three times as often as do non-Maori though we do not claim the differences are significant as the numbers are relatively small.

By contrast, the proportion of those abusing cannabis, methamphetamine or 'other' who subsequently developed schizophrenia is significantly higher $\left(X^{2}=1124\right.$; $\mathrm{df}=1 ; \mathrm{p}<0.001)$ at $10.9 \%$ with the ethnic breakdown rates being 18\% for Maori and 7\% for non-Maori.

\section{DISCUSSION}

\section{Main findings}

Our data indicate that $1.7 \%$ of young adults first presenting to mental health and addiction services who are considered to primarily suffer from alcohol abuse (an F10 categorisation in ICD-10) go on to re-present with a schizophrenia diagnosis (any F20 category in ICD-10) within the subsequent 3 years. By contrast, where the initial presentation was identified as due to a substance use, the 3-year subsequent rate of identification as suffering from schizophrenia was approximately five times greater, at $10.9 \%$. This difference was highly statistically significant. From this study, we are not able to assign responsibility for that increase to any specific drugs so it provides only indirect support for our previously published hypothesis. ${ }^{17}$ It is also possible that some people in the prodromal stages of schizophrenia are more likely to use/abuse drugs than alcohol. However, our demonstrated differences are so dramatic that we consider they must reflect pathogenic drug influences of considerable magnitude.

\section{Limitations}

This study has the strength of reflecting real-life service user data as all presentations to the New Zealand mental health and drug and alcohol services are captured. The concomitant weakness is the absence of the more stringent diagnostic standards of prospective research. At the individual patient level, there is therefore an element of diagnostic unreliability. But we do not see how there could be such a systematic bias of any type which would invalidate our primary finding of at least a fivefold greater rate of the appearance of mental health presentations of what clinicians label as schizophrenia in persons whose initial presentation was for a substance (ab) use disorder, when compared with the rate in those first presenting due to alcohol use.

\section{Implications}

This apparent consequence or side effect of illicit drug use (mainly cannabis and methamphetamine) needs to be further researched. Subject to confirmation of our findings, they have major significance for the development of prevention policies and planning. The finding of the greater rates of appearance of schizophrenia in New Zealand Maori is consistent with our earlier published results and remains a major issue for our nation to better understand and to attempt to rectify.
A number of potentially relevant contributors need to be formally studied in appropriately designed research, ideally prospective and longitudinal. Although we more specifically argue for the relevance of the classificatory term syndrome schizophrenia, our data would fit well with the recent pathogenetic summary by Di Forti $e t$ al. ${ }^{20}$ We doubt that our findings only reflect the situation in New Zealand.

Contributors All three authors contributed to the writing of this article.

Funding The authors have not declared a specific grant for this research from any funding agency in the public, commercial or not-for-profit sectors.

Competing interests None declared.

Patient consent for publication Not required.

Provenance and peer review Not commissioned; externally peer reviewed.

Data availability statement Data may be obtained from a third party and are not publicly available. No data are available. All data relevant to the study are included in the article or uploaded as online supplementary information.

Open access This is an open access article distributed in accordance with the Creative Commons Attribution Non Commercial (CC BY-NC 4.0) license, which permits others to distribute, remix, adapt, build upon this work non-commercially, and license their derivative works on different terms, provided the original work is properly cited, appropriate credit is given, any changes made indicated, and the use is non-commercial. See: http://creativecommons.org/licenses/by-nc/4.0/.

\section{REFERENCES}

1 Jablensky A, Sartorius N, Ernberg G, et al. Schizophrenia: manifestation, incidence and course in different cultures. A World Health Organization ten-country study. Psychol Med 1992.

2 Schizophrenia Working Group of the Psychiatric Genomics Consortium. Biological insights from 108 schizophrenia-associated genetic loci. Nature 2014;511:421-7.

3 Radua J, Ramella-Cravaro V, loannidis JPA, et al. What causes psychosis? An umbrella review of risk and protective factors. World Psychiatry 2018;17:49-66.

4 Tsuang MT, Stone WS, Faraone SV. Genes, environment and schizophrenia. Br J Psychiatry 2001;178(suppl 40):s18-24.

5 Bhugra D, Gupta S, Bhui K, et al. WPA guidance on mental health and mental health care in migrants. World Psychiatry 2011;10:2-10.

6 Bridgeman G, Dyall I. Ngă la o te Oranga Hinengaro Măori. Wellington: Te Puna Kokiri, 1996.

7 Browne O, Wells JE, Scott KM. Te rau Hinengaro: The New Zealand Mental Health Survey. Wellington: Ministry of Health, 2006.

8 Kake TR, Arnold R, Ellis P. Estimating the prevalence of schizophrenia among New Zealand Māori: a capture-recapture approach. Aust N Z J Psychiatry 2008;42:941-9.

9 Tapsell R, Hallet C, Mellsop GW. The rate of mental health service use in New Zealand analysed by ethnicity. Aust Psychiatry 2016.

10 Andréasson S, Engström A, Allebeck P, et al. Cannabis and schizophrenia a longitudinal study of Swedish conscripts. Lancet 1987;330:1483-6.

11 Paparelli A, Di Forti M, Morrison PD, et al. Drug-induced psychosis: how to avoid star gazing in schizophrenia research by looking at more obvious sources of light. Front Behav Neurosci 2011;5:1-7.

12 Carroll A, McSherry B, Yannoulides S. Drug-associated psychoses and criminal responsibility. Behav Sci Law 2008;26:633-53.

13 Murray RM, Quigley H, Quattrone D, et al. Traditional marijuana, high-potency cannabis and synthetic cannabinoids: increasing risk for psychosis. World Psychiatry 2016;15:195-204.

14 Foulds JA, McKetin R. A systematic review of risk factors for methamphetamine-associated psychosis. Aust NZ/Psychiat 2018;52:514-9.

15 Knight G, Hansen S, Connor M, et al. The results of an experimental indoor hydroponic Cannabis growing study, using the 'Screen of Green' (ScrOG) method-Yield, tetrahydrocannabinol (THC) and DNA analysis. Forensic Sci Int 2010;202:36-44.

16 Sara G, Baxter P, Menendez P, et al. Amphetamine availability predicts amphetamine related mental health admissions: a time series analysis. Aust NZJ Psychiat 2018. 
17 Mellsop GW, Tapsell R. Viewpoint: a hypothesis arising from the epidemiology of schizophrenia in New Zealand. ANZJP 2018.

18 Mellsop G, Tapsell R, Menkes DB. Testing a hypothesis arising from the epidemiology of schizophrenia in New Zealand. Gen Psychiatr 2019;32:e100048.
19 Ellis PM, Welch G, Purdie GL, et al. Australasian field trials of the mental and behavioural disorders section of the draft ICD-10. Aust $N$ Z J Psychiatry 1990;24:313-21.

20 Di Forti M, Morgan C, Selton J-P, et al. High potency cannabis and incident psychosis: correcting the causal assumption-authors reply. Lancet 2019.

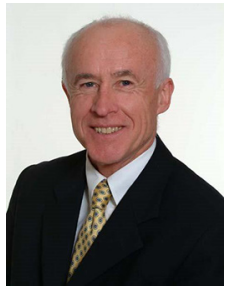

Since 1982 Graham Mellsop has held professorial positions in several Australian and New Zealand Universities. For much of his clinical career he has worked in frontline acute adult psychiatry with some forensic interests. His researches have covered many areas including medical education, clinical epidemiology, forensic psychiatry, and culture and mental health 